\title{
Analyzing the Sea Weather Effects to the Ship Maneuvering in Vietnam's Sea from BinhThuan Province to Ca Mau Province Based on Fuzzy Control Method
}

\author{
Xuan-Kien Dang*, Le Anh-Hoang Ho, Viet-Dung Do \\ Graduate School of Ho Chi Minh City University of Transport \\ Number 2, D3 street, Ward 25, Binh Thanh Disctrict, HoChiMinh City, Viet Nam \\ ${ }^{*}$ Corresponding author, e-mail: dangxuankien@hcmutrans.edu.vn
}

\begin{abstract}
Vietnam is located in the tropical monsoon climate, so there are many storms affecting the marine environment each year. However, Vietnam's sea also has distinct characteristics due to the continental shelf factors, salinity, sea currents and viscosity water. In this paper, the sea weather effects to the ship in the sea area from BinhThuan province to Ca Mau province are analyzed. Specifically, wave, wind and current which are the three main factors affecting the safety of ship are thoroughly examined. Importantly, the survey parameters have been built from the actual operating environment. In addition, maintaining the stability of dynamic positioning system in Vietnam weather conditions is the main point of this study.
\end{abstract}

Keywords: Actual operating environment, Dynamic positioning system, Sea currents, Tropical monsoon climate, Weather conditions

Copyright (c) 2018 Universitas Ahmad Dahlan. All rights reserved.

\section{Introduction}

Maintaining the stability is important for fishing vessel because of its operating characteristics and size. Specifically, it can ensure that the fishing vessels are not capsized and can create favorable conditions for the crew to work safely when engaging in fishing [1-2]. In addition, fishing techniques by trawl or fin mesh play a very important role in stabling ship position and decision success of nets. Due to the tropical monsoon climate of Vietnam's sea area, many storms affecting the fishing environment every year lead to seagoing conditions of continuous movement [3]. In real conditions, with an impact of the vibration, it is very difficult for the fishing vessels to be keft moving in a straight direction. Also, when operating in the particular weather conditions, for example wind or storm, it is easy for the fishing vessel to go in a wrong direction especially when the sea surface changes beacause ship stability is influenced by changes in ship structure parameters or sea characteristics as shown in Figure 1.

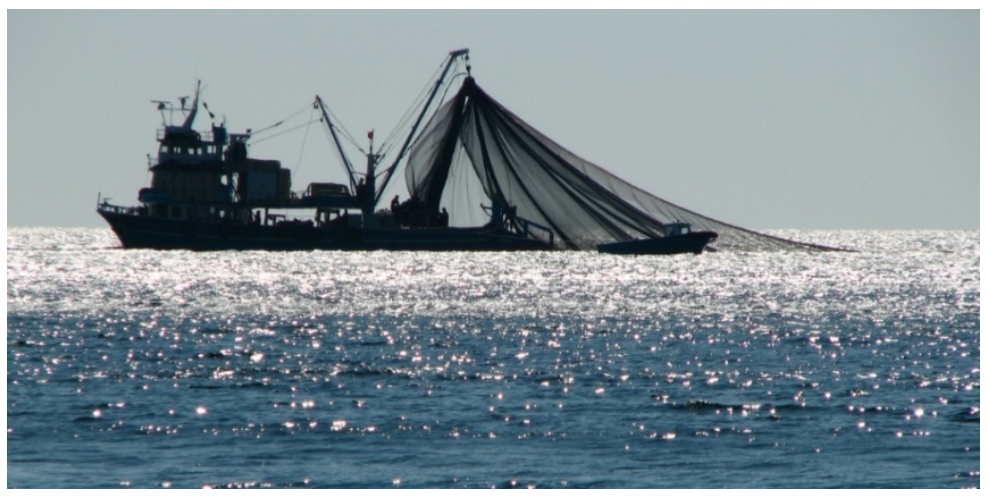

Figure 1. A new kind of a fishing vessel in Vietnam's sea 
This paper aims to analyze the impacts of Vietnam sea environment from Binh Thuan province to $\mathrm{Ca}$ Mau province to maintain stability of vessel position when engaging in fishing. The main environmental impact components include wave, wind and current surveyed with specific characteristics of weather conditions in Vietnam's waters. In addition, moving trains in trajectory in the abnormal weather conditions of the operating environment is a matter of concern in this study.

\section{Typical effects of Vietnam's marine environment}

Storms and tropical depression usually occur from May to November; focus on July and September. Meteorology weather at sea in recent years has been very complicated. Especially storms, tropical depression is increasing in number, seriousness and causing serious damage to fishing boats [7]. In this study, the research group analyzed the impact of the environmental conditions of Vietnam sea area from Binh Thuan province to $\mathrm{Ca}$ Mau province including elements such as wave, wind and current, which are the nonlinearity has the strongest impact on the safety of the operating ship [2]. The wave, wind and current parameters are built according to the Vietnam environment condition that is change able by the monsoon climate. Based on Vietnam Building Code Natural Physical and Climatic Data for Construction(QCXDVN 02:2008/BXD)to find out wind speed and wave height which affecting to the vessel into actual operating case, are illustrated in Figure 2 and Figure 3.

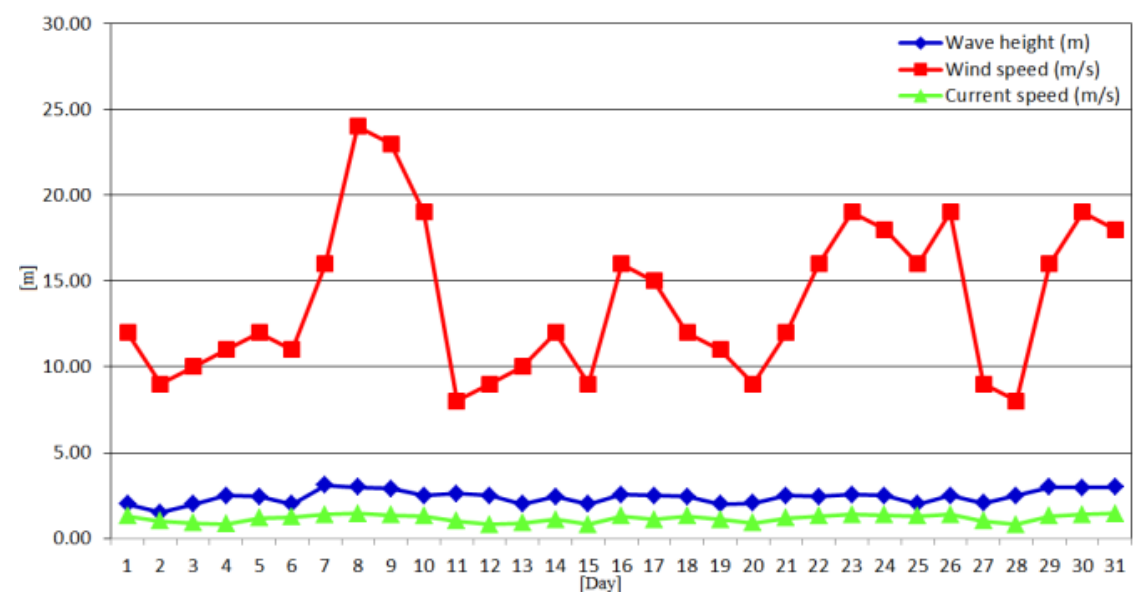

Figure 2. Status of Wave, Wind and Current of Vietnam's Sea in August 2017

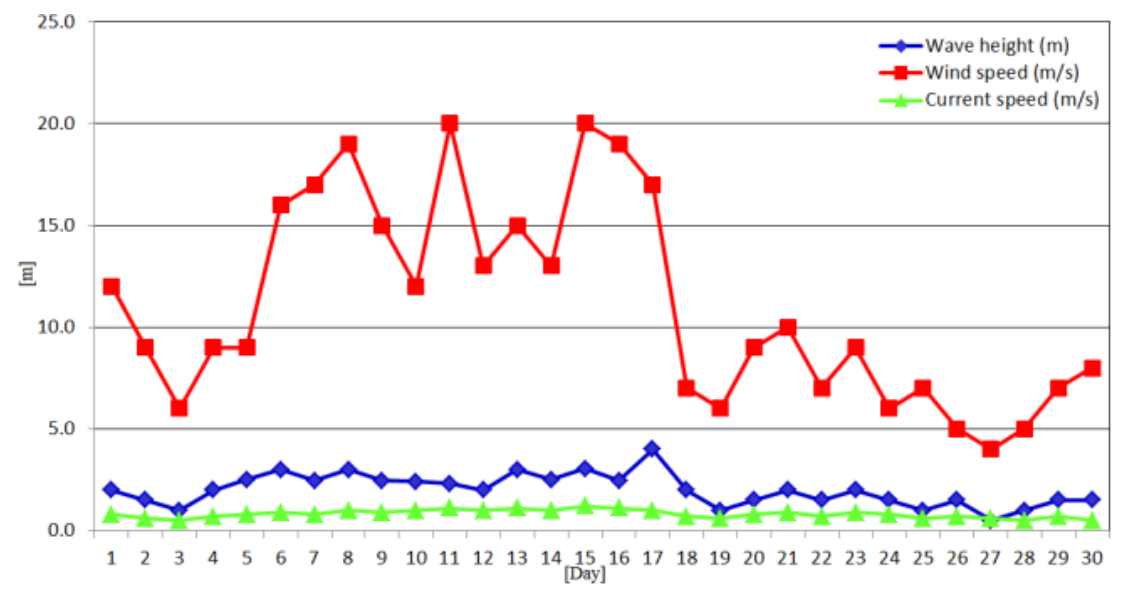

Figure 3. Status of Wave, Wind and Current of Vietnam's Sea in September 2017 


\subsection{Wave surface contruction model}

Ocean waves are physical phenomena that occur in the water layer near the sea surface. The velocity of wave depends on the change in drag, the decrease in performance as well as the increased maneuverability. The research group used mathematical wave model introduced by Ho LAH [11] for modeling the wave surface contruction and determine the wave height which affected the system stabling ship position as in the equation (1).

$$
\tau_{\text {wave }}=\zeta(x, y, t)=\sum_{q=1}^{N} \sum_{r=1}^{M} \sqrt{2 S\left(\omega_{q}, \psi_{r}\right) \Delta \omega \Delta \psi} \sin \left(\omega_{q} t+\phi_{q r}-k_{q}\left(x \cos \psi_{r}+y \sin \psi_{r}\right)\right)
$$

In that, wave amplitude $z_{a q r}$ is given by equation (2).

$$
\zeta_{a q r}=\sqrt{2 S\left(\omega_{q}, \psi_{r}\right) \Delta \omega \Delta \psi}
$$

Where $\Delta \omega$ and $\Delta \psi$ represents one the harmonic wave amplitude, $\psi_{r}, \omega_{q}, \phi_{q r}$ and $S$ represents direction, frequency, phase angle and wave spectrum. The phase angle of all wave components is between 0 and $2 \pi$. In the Earth-fixed coordinate system, the surface in the coordinate $(x, y)$ is given by equation(3).

$$
\zeta_{q r}(x, y, t)=\zeta_{a q r} \sin \left(\omega_{q} t+\phi_{q r}-k_{q}\left(x \cos \psi_{r}+y \sin \psi_{r}\right)\right)
$$

Where $k_{q}=2 \pi / \lambda_{q}$ is the wave number, $\lambda_{q}$ is the wave length, the dispersion relation $\omega_{q}=\sqrt{\mathrm{kg}}$ with $g$ is the acceleration of gravity. The total surface elevation of wave components at coordinate $(x, y)$ and time $(t)$ for $N$ frequences and $M$ direction is illustrated in Figure 4 by using Matlab.

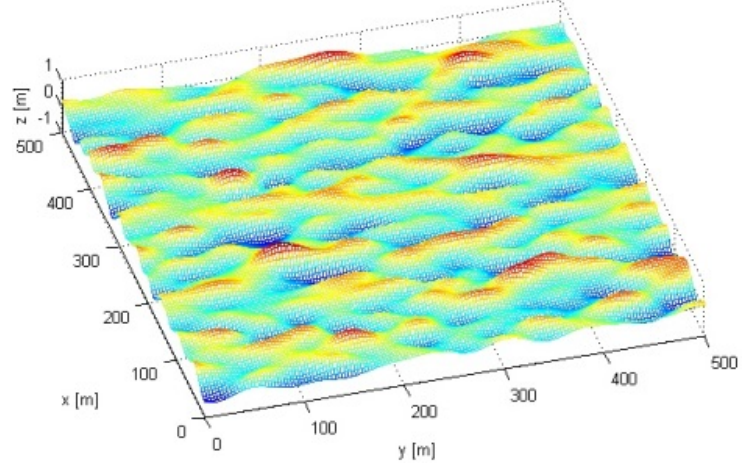

Figure 4. Simulation Result of a Torsethaugen Spectrum

\subsection{Wind contruction model}

The speed, wind direction depends on the location and pressure difference of the atmosphere. However, in each geographic region on earth, the wind has its own characteristic rule. The wind speed [11] which takes an effect on the vessel is defined as $V_{w}$ and $b_{w}$ the wind direction is modeled by the slow variable quantities. The force of the wind in surge, sway and yaw movement is illustrated according to wind power regulations in Vietnam and is described in the equation (4).

$$
\tau_{\text {wind }}=\left[X_{\text {wind }}, Y_{\text {wind }}, N_{\text {wind }}\right]^{T}
$$


Where: $X_{\text {wind }}, Y_{\text {wind }}$ and $N_{\text {wind }}$ are the windforces acting on the vessel can be expressed as Equation 5:

$$
\begin{aligned}
& X_{\text {wind }}=0.5 C_{X} g_{R} \rho_{w} V_{R}^{2} A_{T} \\
& Y_{\text {wind }}=0.5 C_{Y} g_{R} \rho_{w} V_{R}^{2} A_{T} \\
& N_{\text {wind }}=0.5 C_{N} g_{R} \rho_{w} V_{R}^{2} A_{L} L
\end{aligned}
$$

where $C_{X}$ and $C_{Y}$ are the traction, $C_{N}$ is a moment coefficient, $\rho_{w}$ is the density of air, $A_{T}, A_{L}$ are areas of ichnography, $L$ is the overall length of the vessel, $V_{R}$ is the wind speed and $g_{R}$ is the wind direction that effect on the vessel are defined as:

$$
\begin{aligned}
& V_{R}=V_{w} \\
& g_{R}=\beta_{w}-\psi_{L}-\psi_{H}
\end{aligned}
$$

\subsection{Current model}

Current is continuous orientation movement of the sea into the ocean. Current generated by forces acting like earth's magnetic field, wind, temperature, salt salinity, and moon gravity.Assume that the current is constant in both direction and amplitude, so that the current rate $V_{c}$ and the direction $\beta_{c}$ are modeled as the slow variable parameters in the earth axis. The current velocity relative to vessel coordinates is introduced by Fossen [4] as equation(7).

$$
\begin{aligned}
& u_{c}=V_{c} \cos \left(\beta_{c}-\psi_{L}-\psi_{H}\right) \\
& v_{c}=V_{c} \sin \left(\beta_{c}-\psi_{L}-\psi_{H}\right) \\
& \tau_{\text {current }}=\left[u_{c}, v_{c}, 0\right]^{T}
\end{aligned}
$$

Where $\psi_{L}, \psi_{H}$ are angular components affected by low frequency and high frequency quantities, $u_{c}$ and $v_{c}$ are components of the current velocity.

\section{The mathematical model of the system stabling ship's position}

The model system stabling ship's positionaccording to three degrees of freedom including surge, sway and yaw [4], which are showed in Figure 5.

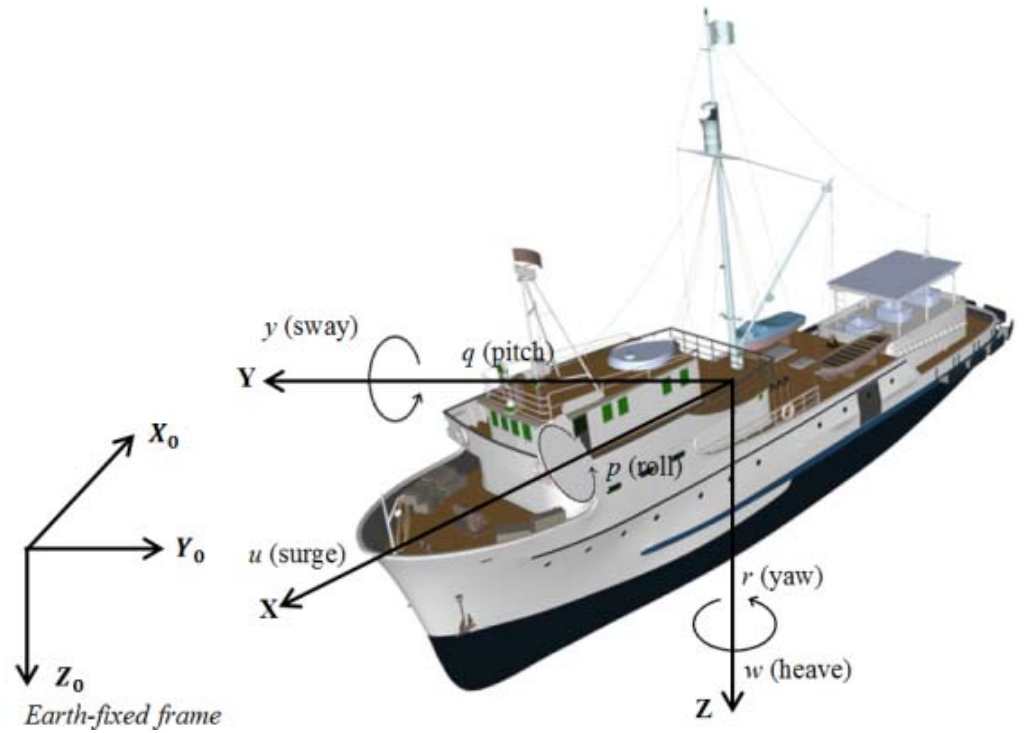

Figure 5. Definition of the Earth-Fixed and the Ship-Fixed Reference Frames 
The position $(x, y)$ and heading $(\psi)$ of the ship in the absolute coordinate systemare expressed in the vector $\eta=(x, y, \psi)^{T}$. The vector $v=(u, v, r)^{T}$ represents surge velocity $u$, sway velocity $v$ and yaw $r$ of the ship on the body-fixed frame [5]. Model representation of the dynamic positioning system with three degrees of freedom, namely, surge, sway, yaw and external force acting is shown in equations (8)-(9).

$$
\begin{aligned}
& \dot{\eta}=J(\eta) v \\
& M \dot{v}+D v=\tau+\tau_{\text {envi }}
\end{aligned}
$$

The rotation matrix $J(\psi)$, the inertia matrixMand the damping matrix $D$ are given by

$$
\begin{aligned}
& J(\psi)=\left[\begin{array}{ccc}
\cos (\psi) & -\sin (\psi) & 0 \\
\sin (\psi) & \cos (\psi) & 0 \\
0 & 0 & 1
\end{array}\right] \\
& M=\left[\begin{array}{ccc}
m-X_{\dot{u}} & 0 & 0 \\
0 & m-Y_{\dot{v}} & m x_{G}-Y_{\dot{r}} \\
0 & m x_{G}-N_{\dot{v}} & I_{z}-N_{\dot{r}}
\end{array}\right] \\
& D=\left[\begin{array}{ccc}
-X_{u} & 0 & 0 \\
0 & -Y_{v} & m u_{0}-Y_{r} \\
0 & -N_{v} & m x_{G} u_{0}-N_{r}
\end{array}\right]
\end{aligned}
$$

Where $m$ is a shipmass, $I_{Z}$ is the moment of inertia about the body-fixed $Z$-axis, $x_{G}$ represents the Ication of $G$ in $x$-axis direction, $u_{0}$ is velocity component at mid-ship. The inertia quantities are expressed as follows:

$$
X_{\dot{u}} \triangleq \frac{\partial X}{\partial \dot{u}}, Y_{\dot{v}} \triangleq \frac{\partial Y}{\partial \dot{v}}, N_{\dot{r}} \triangleq \frac{\partial N}{\partial \dot{r}}, Y_{\dot{r}} \triangleq \frac{\partial Y}{\partial \dot{r}}, N_{\dot{v}} \triangleq \frac{\partial N}{\partial \dot{v}}
$$

In most DP applications, $D$ is the damping matrix and $M$ is the inertia matrix including added mass effects, which is symmetric and positive definite. However, for low speed applications the damping matrix has $N_{v}=Y_{r}$. The force components and moments of linear decline are given by equation (13):

$$
X_{u} \triangleq \frac{\partial X}{\partial u}, Y_{v} \triangleq \frac{\partial Y}{\partial v}, N_{\dot{r}} \triangleq \frac{\partial N}{\partial r}, Y_{\dot{r}} \triangleq \frac{\partial Y}{\partial r}, N_{\dot{v}} \triangleq \frac{\partial N}{\partial v}
$$

The control vector $\tau$ produced by propeller and thruster systems. Vector $\tau_{\text {envi }}$ represents the impact forces from environmentalfactors, including wave, wind and current component effect on the vessel follows:

$$
\tau=\left[\tau_{x}, \tau_{y}, \tau_{\psi}\right]^{T}
$$




\section{Simulation Results and Remark}

\subsection{PID controller design}

The PID controller parameters shown in equation (15) are constructed base with the Ziegler-Nichols method as shown in Figure 6. Compared to the coefficients in [11], thus correcting the optimal control coefficient with the dynamic structure of the fishing ship.

$$
\tau_{P I D}=K_{p} z_{1}(t)+K_{i} \int_{0}^{t} z_{1}\left(\tau_{t}\right) d \tau_{t}+K_{d} \dot{z}_{1}(t)
$$

Where: $K_{p}, K_{i}$ and $K_{d}$ are the controller gains with $K_{p}=\operatorname{diag}\left(6 e^{5}, 6 e^{5}, 6 e^{9}\right), K_{i}=\operatorname{diag}(10,10,150)$ and $K_{d}=\operatorname{diag}\left(9 e^{6}, 9 e^{6}, 9 e^{9}\right)$.

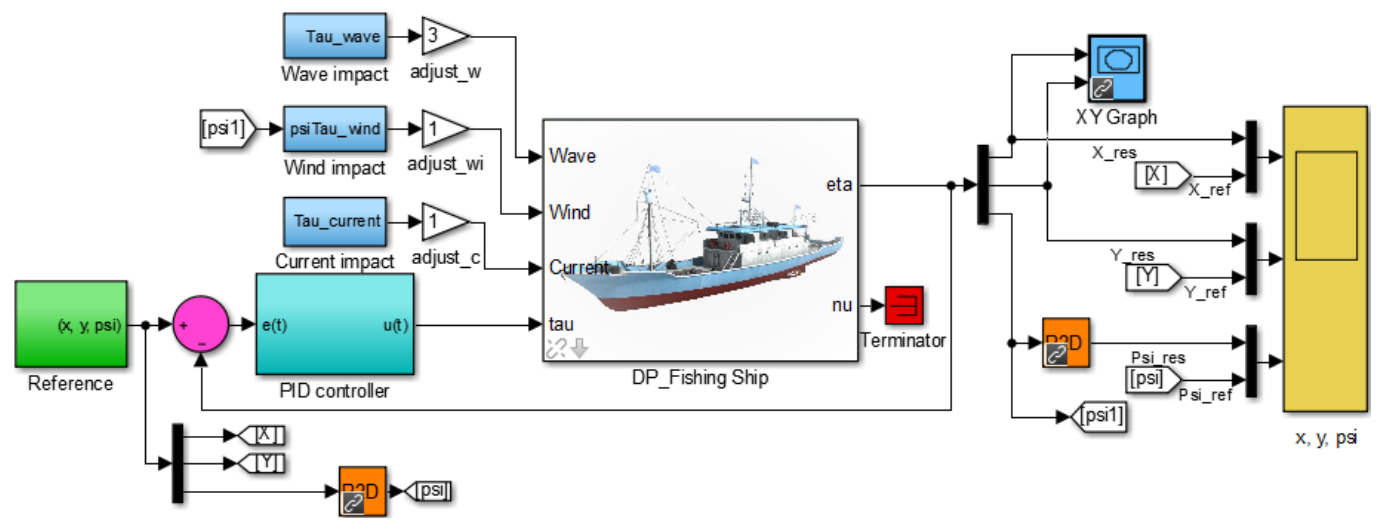

Figure 6. PID Controller Schematic for Stabling Ship's Position

\subsection{Fuzzy controller design}

In oder to reduce nonlinear characteristics of the dynamic positioning system that are caused by unexpected effects from Binh Thuan province to $\mathrm{Ca}$ Mau province waters. We considers the fuzzy controller has a double-inputs $\mathrm{e}_{\eta}, \mathrm{de}_{\eta} / \mathrm{dt}$, and single-output $\tau$ as shown in Figure 7.

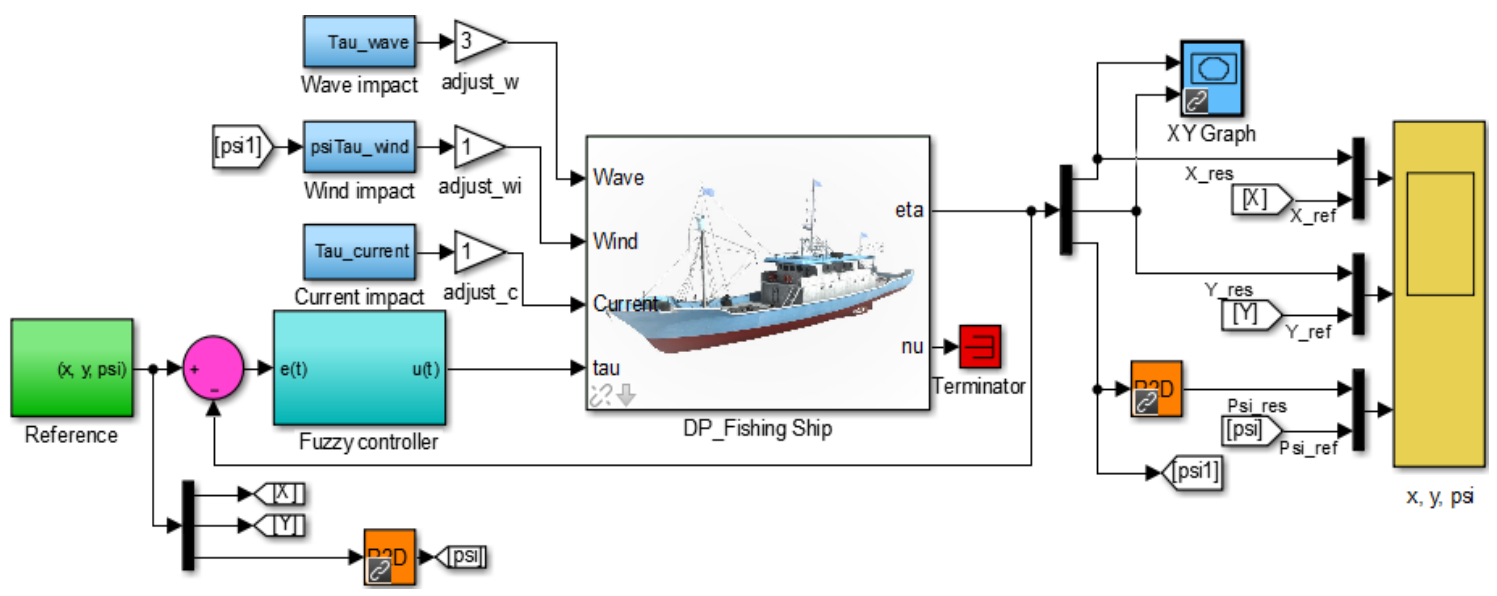

Figure 7. Fuzzy Controller Schematic for Stablingship's Position 
The process of fuzzy inference system is connected with membership functions, fuzzy logic operators, and if-then rules. In this paper, using Takagi-sugeno fuzzy inference method, the membership function collections are set as below:

$$
\begin{aligned}
& \mathrm{e}_{\eta} \quad:\left\{\begin{array}{llll}
\mathrm{NE} & \mathrm{NS} & \mathrm{ZEPS} & \mathrm{PO}\}
\end{array}\right. \\
& \mathrm{de}_{\eta} / \mathrm{dt}:\left\{\begin{array}{lll}
\mathrm{NS} & \mathrm{ZE} & \mathrm{PS}
\end{array}\right\} \\
& \tau \quad:\{\mathrm{NE} \text { NSS NSZE PS PSS PO }
\end{aligned}
$$

The fuzzy rules are using same as in Table 1. In order to design a Takagi-sugeno fuzzy logic with a compact rule base, the rule notation form within $\mathrm{B}_{\mathrm{k}}^{\mathrm{i}}$ is a binary variable that determines the consequence of the rule given as follow:

$$
R_{i} \text { : If } \hat{e}_{1} \text { is } A_{k 1}^{i} \ldots \ldots \ldots \text { and } \hat{e}_{n} \text { is } A_{k n}^{i} \text { then } u_{f k} \text { is } B_{k}^{i} \text {, }
$$

where $A_{k 1}^{i}, A_{k 2}^{i}, \ldots A_{k n}^{i}$ and $B_{k}^{i}$ are fuzzy sets. By using the Max-Prod inference rule, the singleton fuzzifier and the center averaged defuzzifier. The fuzzy output can be expressed as bellows:

$$
\mathrm{u}_{\mathrm{fk}}=\frac{\sum_{\mathrm{i}=1}^{\mathrm{h}} \theta_{\mathrm{k}}^{-\mathrm{i}}\left[\prod_{\mathrm{j}=1}^{\mathrm{n}} \mu_{\mathrm{A}_{\mathrm{kj}}^{\mathrm{i}}}\left(\hat{\mathrm{e}}_{\mathrm{j}}\right)\right]}{\sum_{\mathrm{i}=1}^{\mathrm{h}}\left[\prod_{\mathrm{j}=1}^{\mathrm{n}} \mu_{\mathrm{A}_{\mathrm{kj}}^{\mathrm{i}}}\left(\hat{\mathrm{e}}_{\mathrm{j}}\right)\right]}=\theta_{\mathrm{k}}^{\mathrm{T}} \varphi_{\mathrm{k}}(\hat{\mathrm{e}})
$$

For $\mu_{A_{k j}^{i}}\left(\hat{e}_{j}\right)$ is the fuzzy membership function, $h$ is the total number of If-Then rules, $\theta_{\mathrm{k}}^{-\mathrm{i}}$ is the point at which $\mu_{\mathrm{B}_{\mathrm{k}}^{\mathrm{i}}}\left(\theta_{\mathrm{k}}^{-\mathrm{i}}\right)=1$ and $\varphi_{\mathrm{k}}(\hat{\mathrm{e}})=\left[\varphi_{\mathrm{k}}^{1}, \varphi_{\mathrm{k}}^{2}, \ldots, \varphi_{\mathrm{k}}^{\mathrm{h}}\right]^{\mathrm{T}} \in \mathrm{R}^{\mathrm{h}}$ is the fuzzy basis vector with $\varphi_{\mathrm{k}}^{\mathrm{i}}$ is defined as:

$$
\varphi_{\mathrm{k}}^{\mathrm{i}}(\hat{\mathrm{e}})=\frac{\left.\prod_{\mathrm{j}=1}^{\mathrm{n}} \mu_{A_{\mathrm{kj}}^{\mathrm{i}}}\left(\hat{\mathrm{e}}_{\mathrm{j}}\right)\right]}{\sum_{\mathrm{i}=1}^{\mathrm{h}}\left[\prod_{\mathrm{j}=1}^{\mathrm{n}} \mu_{A_{\mathrm{kj}}^{\mathrm{i}}}\left(\hat{\mathrm{e}}_{\mathrm{j}}\right)\right]}
$$

In fact, environmental impacts often make the control signal to be erroneous that caused by the change of object dynamic characteristic. If the controller does not cover the control error, the quality control is not high. The automatic tuning concepts of the fuzzy controller is deployed in corresponding to the input error. Thereby, the control error is reduced as well as the control goal is maintained. The membership functions describe these input/output characteristics of the vessel translation motion as a detail in Figure 8.

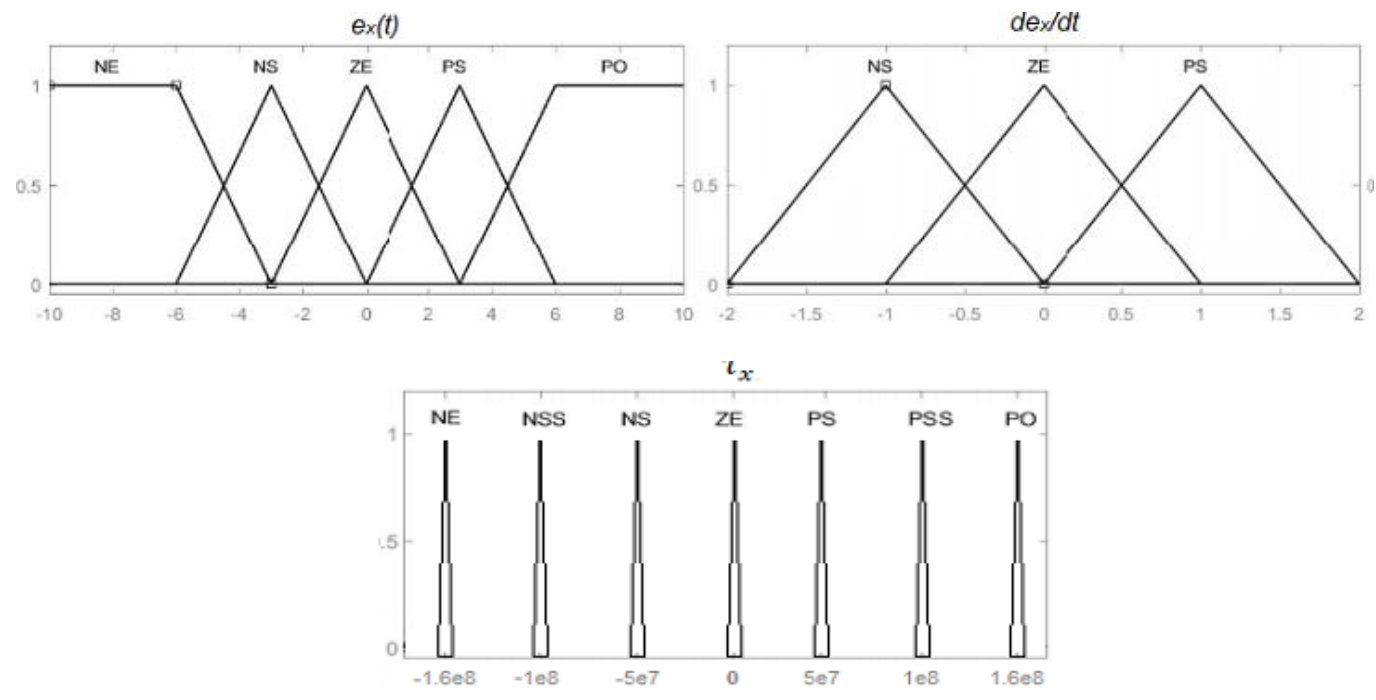

Figure 8. The membershipfunctions of error input e(t), velocity of error de/dt and impact force $\tau$.

Analysis the Sea Weather Effects to the ship Maneuvering in Vietnam's ... (Xuan Kien Dang) 
The fuzzy control rules are a context functions that combine prefix state variables to the process control variables. Composition law and inference mechanism of fuzzy relation are shown in Table 1.

Table 1. The synthesis of composition law

\begin{tabular}{|c|c|c|c|c|}
\hline & \multirow{2}{*}{$\tau_{\mathrm{x}} / \boldsymbol{\tau}_{\mathrm{y}} / \boldsymbol{\tau}_{\boldsymbol{\psi}}$} & \multicolumn{3}{|c|}{$\mathrm{de} / \mathrm{dt}$} \\
\hline & & NS & ZE & PS \\
\hline \multirow{5}{*}{$e(t)$} & $\mathrm{NE}$ & $\mathrm{NE}_{\mathrm{X}} / \mathrm{NE}_{\mathrm{Y}} / \mathrm{NE}_{\psi}$ & $\mathrm{NSS}_{\mathrm{X}} / \mathrm{NSS}_{\mathrm{Y}} / \mathrm{NSS}_{\psi}$ & $\mathrm{NS}_{\mathrm{X}} / \mathrm{NS}_{\mathrm{Y}} / \mathrm{NS}_{\Psi}$ \\
\hline & NS & $\mathrm{NSS}_{\mathrm{X}} / \mathrm{NSS}_{\mathrm{Y}} / \mathrm{NSS}_{\psi}$ & $\mathrm{NS}_{\mathrm{X}} / \mathrm{NS}_{\mathrm{Y}} / \mathrm{NS}_{\Psi}$ & $\mathrm{ZE}_{\mathrm{X}} / \mathrm{ZE}_{\mathrm{Y}} / \mathrm{ZE}_{\psi}$ \\
\hline & ZE & $\mathrm{NS}_{\mathrm{X}} / \mathrm{NS}_{\mathrm{Y}} / \mathrm{NS}_{\psi}$ & $\mathrm{ZE}_{\mathrm{X}} / \mathrm{ZE}_{\mathrm{Y}} / \mathrm{ZE}_{\psi}$ & $\mathrm{PS}_{\mathrm{X}} / \mathrm{PS}_{\mathrm{Y}} / \mathrm{PS}_{\Psi}$ \\
\hline & PS & $\mathrm{ZE}_{\mathrm{X}} / \mathrm{ZE}_{\mathrm{Y}} / \mathrm{ZE}_{\psi}$ & $\mathrm{PS}_{\mathrm{X}} / \mathrm{PS}_{\mathrm{Y}} / \mathrm{PS}_{\Psi}$ & $\mathrm{PSS}_{\mathrm{X}} / \mathrm{PSS}_{\mathrm{Y}} / \mathrm{PSS}_{\psi}$ \\
\hline & $\mathrm{PO}$ & $\mathrm{PS}_{\mathrm{X}} / \mathrm{PS}_{\mathrm{Y}} / \mathrm{PS}_{\psi}$ & $\mathrm{PSS}_{\mathrm{X}} / \mathrm{PSS}_{\mathrm{Y}} / \mathrm{PSS}_{\psi}$ & $\mathrm{PO}_{\mathrm{X}} / \mathrm{PO}_{\mathrm{Y}} / \mathrm{PO}_{\psi}$ \\
\hline
\end{tabular}

\subsection{Simulation parameters}

The structural parameters of fishing vessels are showed in Table 2. The research group has simulated adverse effects with detailedparameters for each of the components as

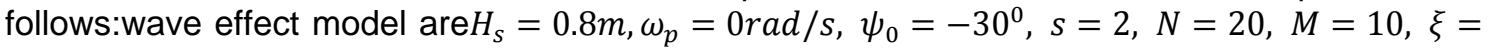
$3, k=0.005$ and $\psi_{\text {lim }}=0$; wind effect model $A_{L}=2.4, A_{T}=9.34, V_{\omega}=2 \mathrm{~m} / \mathrm{sand} \beta_{\omega}=20^{0}$; current effect $V_{C}=2 \mathrm{~m} / \mathrm{s}, \psi_{L}=\psi_{H}=0$ and $\beta_{C}=30^{\circ}$.

Table 2. The structural parameters of fishing vessels

\begin{tabular}{lc}
\hline \multicolumn{1}{c}{ DESCRIPTION } & DIMENSION \\
\hline Length overall (LMAX) & $30.8 \mathrm{~m}$ \\
Length between perpendiculars (LPP) & $27.8 \mathrm{~m}$ \\
Beam (B) & $7.5 \mathrm{~m}$ \\
Design draft (d) & $2.7 \mathrm{~m}$ \\
Main machine(N_e) & $820 \mathrm{HP}$ \\
\hline
\end{tabular}

$$
\begin{gathered}
D=\left[\begin{array}{ccc}
5.0242 e 4 & 0 & 0 \\
0 & 2.7229 e 5 & -4.3933 e 6 \\
0 & -4.3933 e 6 & 4.1894 e 8
\end{array}\right] \\
M=\left[\begin{array}{ccc}
5.3122 e 6 & 0 & 0 \\
0 & 8.2831 e 6 & 0 \\
0 & 0 & 3.7454 e 9
\end{array}\right]
\end{gathered}
$$

\subsection{Results and Analysis}

To evaluate the performance and the stability of the proposed fuzzy control method, we compared the PID control method [11] and our fuzzy control proposed method in the simulation. The simulation results in case of ideal conditions of the sea (small environmental impact), the position of the ship is kept stable, precisely when traversed in either the direction and surge or yaw in both method using the PID controller and fuzzy controller as shown in Figure 9. When considered in terms of actual effects under the influence of unwanted effects, the position of the ship is no longer stable and fluctuates gradually with varying amplitude. In addition, the maneuvering of a given trajectory is also unlikely to occur because the angle error of deviation and the direction of movement is relatively large. The simulation results are shown in Figure 9 and Figure 10. 

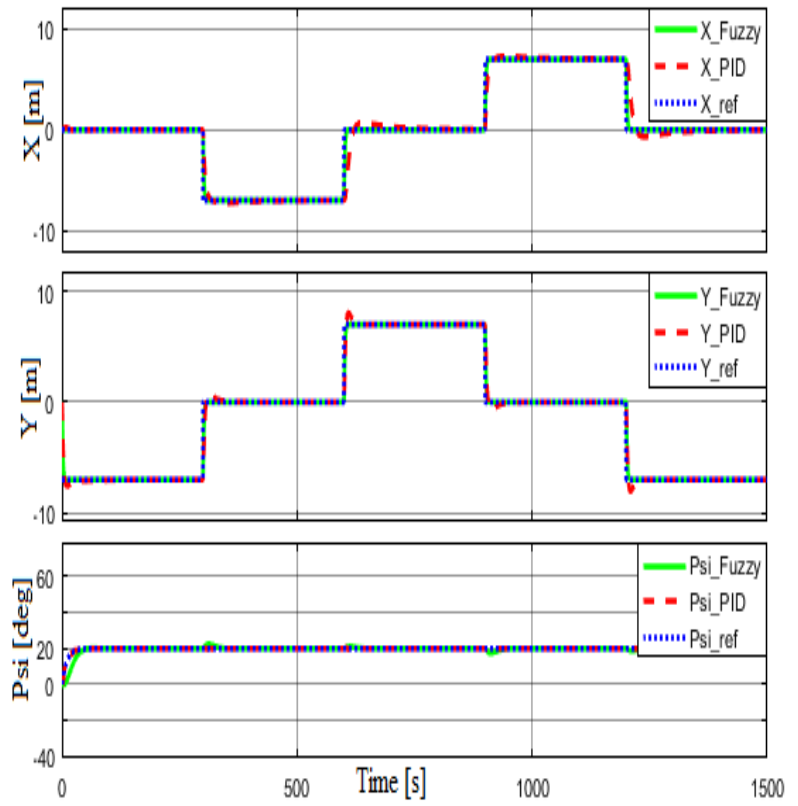

Figure 9. The system outputs $X, Y$, Psi in case of the effect of small environmental impact (Level 1)
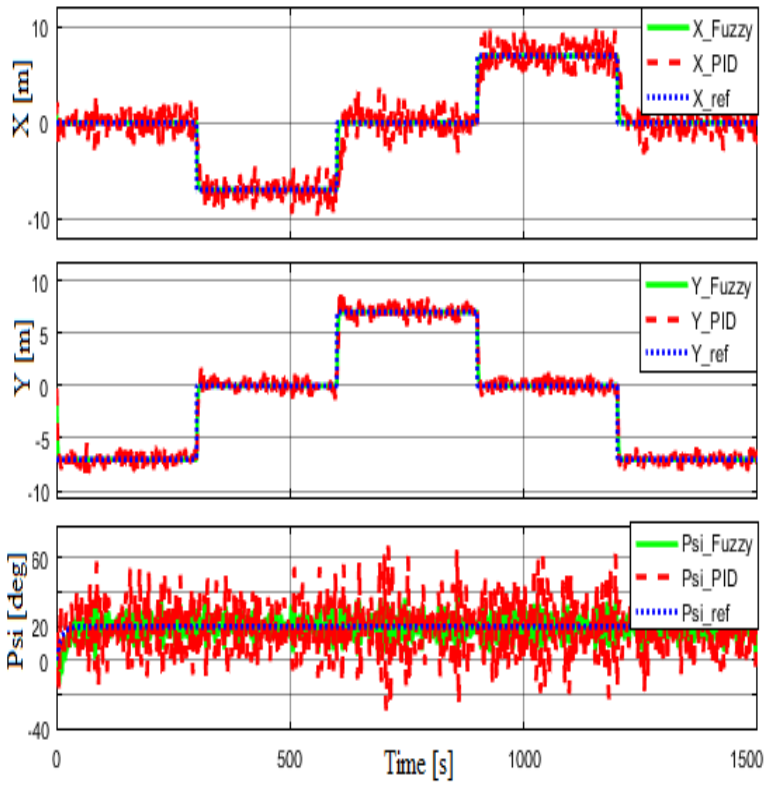

Figure 10. The outputs $X, Y$, Psi of the simulation in case of under the effect of big environmental impact (Level 5)

Finally, we consider the simulation results of the ship maneuvering of a given trajectory under the effect of big environmental impact (Level 5) showed in Figure 11 and Figure 12. The system is stable in case of using fuzzy control method, but the position is becomes unacceptable in case of using Do.et,al method [11]. These results show that the proposed fuzzy method can eliminate the effect of of big environmental impact (Level 5) event when the ship is operating in difficulty rating sea conditions in Vietnam. 


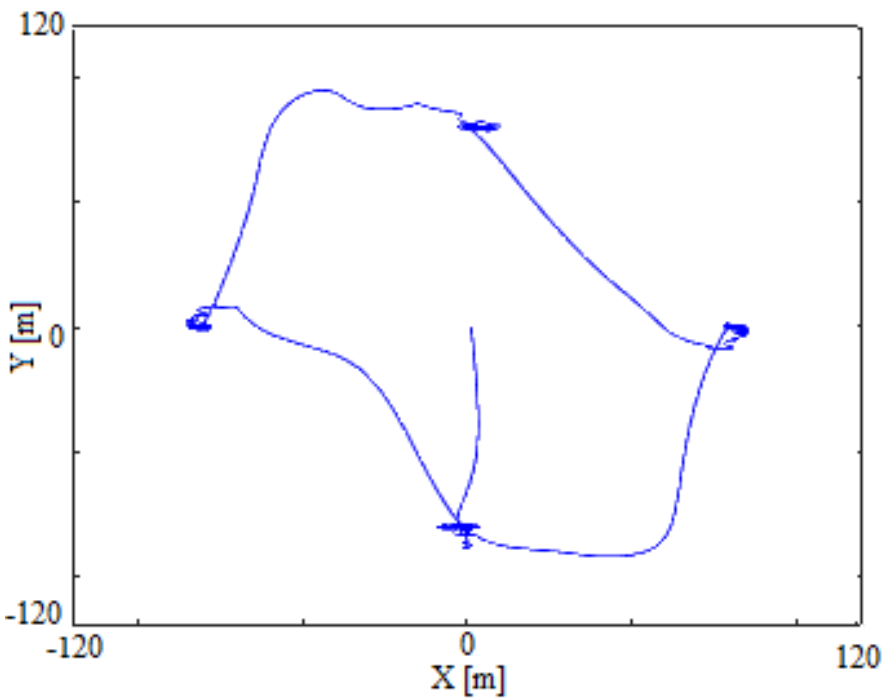

Figure 11. PID control for ship maneuvering of a given trajectory under the effect of big environmental impact (Level 5)

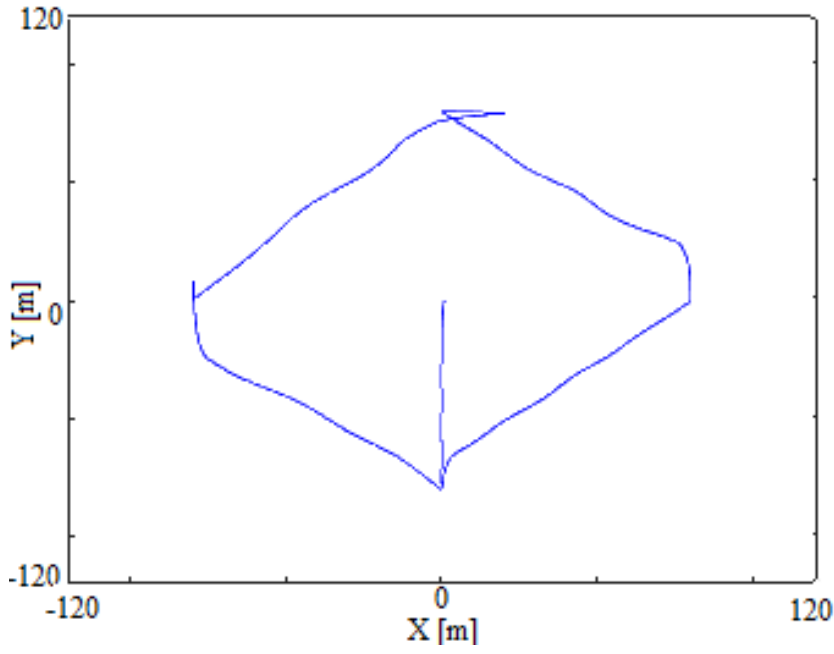

Figure 12. Fuzzy control for ship maneuvering of a given trajectory under the effect of big environmental impact (Level 5)

\section{Conclusion}

In this paper, we analyze environmental factors influencing the movement of the ship with the weather characteristics from Binh Thuan province to Ca Mau province sea area. The ship maneuvering process following the trajectory under the effect of big environmental impact is controlled successfully by the proposed fuzzy controller. The simulation results show that our approach provides better performance and can be successfully applied in practical engineering when facing with some ship control problems related to environmental disturbances. The achieved results are more limited when the ship moves in real weather conditions and therefore there is a need for future research with higher requirements for quality control. 


\section{References}

[1] Nguyen, V. T. Stability and Perils Faced by Fishing Boarts. Journal of Marine Science and Technology. 2007; 3-6.

[2] Nguyen, V. T., Pham, V. T. Cause of the Ship Collision and Some Precautions. Journal of Marine Science and Technology. 2011; 49-53.

[3] Dinh, V. U., Nguyen, K. C., Ha, T. H., Nguyen, N. M. Study on the effects of climate change on the East Sea surface flow field. VNU Journal of Science. 2015; 269-276.

[4] Fossen, T. I. Handbook of Marine Craft Hydrodynamics and Motion Control. United Kingdom: John Wiley \& Sons, Ltd. 2011.

[5] Sandaruwan, D., Kodikara, N. Keppitiyagama, C., Rosa, R.. A Six Degrees of Freedom Ship Simulation System for Maritime Education. The International Journal on Advances in ICT for Emerging Regions, 2010; 34-47.

[6] Pham, S. H., Nguyen, K. V. (2012), "Current Characteristics in the Waters of KhanhHoa Province during Southwest Monsoon Period", Journal of Marine Science and Technology, pp.57-66.

[7] Lee, S. G. Marine Accident Integrated Analysis System. Journal of Asia Maritime and Fisheries Universities Forum. 2016; 49-61.

[8] QCXDVN 02:2008/BXD. Vietnam Building CodeNatural Physical \& Climatic Data for Construction. 2008.

[9] Fossen, T. I. Marine Control Systems - Guidance, Navigation and Control of Ship, Rigs and Underwater Vehicles. Marine Cybernetics; Trondheim, Norway. 2002.

[10] Do, V. D., Dang, X. K., Le, A. T. Fuzzy Adaptive Interactive Algorithm for Rig Balancing Optimization. International Conference on Recent Advances in Signal Processing, Telecommunication and Computing, IEEE conference. 2017; 143-148.

[11] Do, V. D., Dang, X. K., Ho, L. A. Enhancing Quality of the Dynamic Positioning System for Supply Vessel under Unexpected Impact based on Fuzzy Takagi-Sugeno Algorithm. Journal of Marine Science and Technology. 2017. 